\title{
Eksplorasi Fungi Mikoriza Arbuskula pada Perkebunan Kelapa Sawit PT. Lembah Bhakti di Rawa Singkil dengan Kultur Trapping
}

(Exploration of Arbuscular Mycorrhizal Fungi on Oil Palm Plantation PT. Lembah Bhakti at Singkil Swamp with Trapping Culture)

\author{
Safran $^{1}$, Ashabul Anhar ${ }^{1}$, Fikrinda $^{1 *}$ \\ ${ }^{1}$ Program Studi Agroteknologi, Fakultas Pertanian, Universitas Syiah Kuala
}

\begin{abstract}
Abstrak. Penelitian ini dilakukan untuk mengeksplorasi fungi mikoriza arbuskula (FMA) pada perkebunan kelapa sawit PT Lembah Bhakti dengan kultur trapping. Populasi spora dan kolonisasi FMA pada akar kelapa sawit di amati pada kelapa sawit umur 5 tahun, 10 tahun, dan 15 tahun dengan tiga media pembawa (zeolit, pasir dan biochar). Terdapat dua genus yang ditemukan pada rizosfir kelapa sawit yaitu Glomus dan Acaulospora. Glomus merupakan genus yang dominan dan Glomus sp1 merupakan spesies yang lebih banyak. Hasil penelitian menunjukkan kepadatan spora tertinggi didapatkan pada rizosfer kelapa sawit umur 5 tahun ( 65 spora per 50g tanah) sedangkan kolonisasi akar tertinggi didapatkan pada umur 10 tahun $(39,6$ $\%)$. Zeolit merupakan media pembawa terbaik dalam kultur trapping yang ditunjukkan oleh lebih tingginya kepadatan spora maupun kolonisasi akar.
\end{abstract}

Kata kunci : Glomus, Acaulospora, Media, Perkebunan kelapa sawit

bstract. This research was conducted to explore the arbuscular mycorrhizal fungi (AMF) at oil palm plantation of PT Lembah Bhakti with trapping culture. AMF Spore populations at colonization at the root of palm oil were observed in oil palm aged were observation at 5 years, 10 years, and 15 years with three carrier media (zeolite, sand and biochar). There are two genera found Glomus and Acaulospora. Glomus was the dominant genus and Glomus sp1 was a larger species. The results showed that the highest spore density was found in the 5-year-old palm oil rizosphere (65 spores per $50 \mathrm{~g}$ of land) while the highest root colonization was obtained at age 10 (39.6\%). Zeolite was the best carrier in trapping culture which is shown by higher spore density and root colonization.

Keywords: Glomus, Acaulospora, Medium, Oil palm plantation

\section{PENDAHULUAN}

Fungi mikoriza arbuskula (FMA) adalah kelompok fungi yang bersimbiosis mutualisme dengan akar tanaman (Suamba, Wirawan dan Adiartayasa 2014). Menurut Smith dan Read (2008), FMA dapat berasosiasi dengan 90\% jenis tanaman dikotiledon, monokotiledon. Beberapa jenis tanaman yang dapat bersimbiosis dengan FMA adalah tebu, teh, tembakau, palem, kopi, karet, kapas, jeruk, kakao dan kelapa sawit (Sunarti et al.,2004; Bolan, 1991)

Selain jenis tanaman, keberadaan FMA juga dipengaruhi oleh umur tanaman (Guadarrama et al., 2008; Widiastuti, 2006). Arman et al., (2015) menemukan jumlah dan jenis FMA terbanyak pada rizosfer tanaman kelapa sawit berumur 7 tahun dibandingkan dengan umur 2-3 bulan, 2 tahun dan 10 tahun.

FMA dapat ditemukan hampir pada semua bentang lahan, termasuk lahan gambut (Sibarani, 2011). Rawa Singkil merupakan satu dari tiga rawa gambut yang cukup luas di Provinsi Aceh dengan luasan areal hingga 100.000 hektar (Djufri, Abdullah dan Muchlisin, 2013). Lahan ini banyak dikonversi menjadi perkebunan kelapa sawit (Ariantiningsih 2008) yang dikelola oleh masyarakat itu sendiri dan beberapa perusahaan swasta, salah satunya adalah PT. Lembah Bhakti. Area perkebunan kelapa sawit di PT. Perkebunan Lembah Bhakti terletak di dua kecamatan yaitu Kecamatan Gunung Meriah dengan luas

Corresponding author: yusdarzakaria@ unsyiah.ac.id

JIM Pertanian Unsyiah - AGT, Vol. 2, No. 3, Agustus 2017: 38-48 
area tanam 2.560,99 dan Kecamatan Singkil Utara dengan luasan area tanam 3.346,89 ha ( PT. Perkebunan Lembah Bhakti, 2014).

Eksplorasi FMA secara langsung dari rizosfer alami sering memperoleh hasil yang rendah (Rengganis, 2013). Untuk mengatasi hal tersebut dapat dilakukan dengan kultur trapping (Siregar, 2014; Sibarani, 2011). Penggunaan media yang sesuai dapat mempengaruhi perkembangan FMA pada kultur trapping (Prasetia, 2012). Berbagai media dapat digunakan sebagai media tumbuh pada kultur trapping, misalnya tanah, pasir, zeolit, dan arang sekam (Nurbaity et al., 2009; Prematuri dan Faiqoh, 1999; Redecker et al., 1998)

Berdasarkan pemikiran tersebut penelitian ini dilakukan untuk mengeksplorasi keberadaan FMA lokal di rizosfer kelapa sawit pada perkebunan PT. Lembah Bhakti di kawasan Rawa Singki dengan mengunakan kultur trapping.

\section{MATERI DAN METODE}

\section{Pengambilan sampel}

Penelitian ini merupakan Sampel tanah dan akar diambil di rizosfer berbagai umur kelapa sawit yaitu: 5 tahun, 10 tahun dan 15 tahun pada kedalaman 0-20 cm. Sampel tanah dari tanaman kelapa sawit berumur 5 dan 15 tahun diambil di Afdeling Carli yang berlokasi di Desa Pandan Sari Kecamatan Gunung Meriah, Aceh Singkil, sedangkan umur 10 tahun tahun diambil di Afdeling Fanta yang terletak di Desa Kampung Baru Kecamatan Singkil Utara, Aceh Singkil. Sampel tanah dan akar tanaman untuk setiap ulangan pada setiap umur tanaman merupakan komposit dari lima tanaman dengan jarak 9m dan sedangkan jarak antar ulangan adalah $25 \mathrm{~m}$.

\section{Analisis kimia tanah}

Sampel tanah yang digunakan untuk kultur trapping terlebih dahulu dianalisis kimia tanah dilaksanakan di Laboratorium Departemen Ilmu Tanah Sumberdaya Lahan, Fakultas Pertanian, IPB. Parameter yang diamati: $\mathrm{pH}$ (Elektrometrik), C-organik (pembakaran/pengabuan/ gravimetrik), N-total (kjeldhal), P-tersedia (Bray 1), Kdd (Ekstraksi dengan $1 \mathrm{~N} \mathrm{NH}_{4} \mathrm{OAc} \mathrm{pH} 7,0$ ), KTK (Ekstraksi dengan $1 N \mathrm{NH}_{4} \mathrm{OAc} \mathrm{pH} 7,0$ )

\section{Isolasi Spora FMA}

Teknik yang digunakan untuk mengisolasi spora FMA adalah teknik tuang saring basah (Pacioni, 1992 dalam Brundrett et al., 1996) dan dilanjutkan dengan teknik sentrifugasi (Brundrett et al., 1996). Tanah sebanyak $50 \mathrm{~g}$ dilarutkan dalam $500 \mathrm{ml}$ airselama 30 menit. Selanjutnya suspensi tanah tersebut disaring dengan saringan bertingkat yang berukuran $600,250,106,53$, dan $38 \mu \mathrm{m}$ dengan menggunakan air mengalir sampai jernih. Hasil saringan dari sari saringan berukuran 250, 106, 53, dan $38 \mu \mathrm{m}$ ditransfer ke tabung sentrifus dan disentrifusi selama 5 menit dengan kecepatan $2500 \mathrm{rpm}$. Supernatan hasil sentrifus dibuang, danendapan diresuspensi dengan larutan sukrosa 50\% serta disentrifus kembali selama satu menit dengan kecepatan $2500 \mathrm{rpm}$. Spora dipanen dengan cara menyaring supernatan dengan menggunakan saringan berukuran $38 \mu \mathrm{m}$. Untuk menghilangkan sisa sukrosa,spora dalam saringan dibilas dengan air, dan spora yang tertampung diamati dengan menggunakan mikroskop dissecting. 


\section{Identifikasi Spora FMA}

Identifikasi spesies FMA dilakukan dengan mengamati karakter morfologinya yang meliputi bentuk, ukuran dan warna spora di bawah mikroskop cahaya (100-400 x). Spora tersebut diidentifikasi berdasarkan dengan menggunakan Manual for the Identification of Mychorrhiza Fungi seperti dideskripsikan oleh Schenk dan Perez (1990).

\section{Kolonisasi FMA Pada Akar Tanaman}

Akar-akar kelapa sawit dari berbagai umur tanaman, dicuci dengan air dan djernihkan dengan $10 \% \mathrm{KOH}$ dan $100 \mathrm{~mL}-1 \mathrm{~b} / \mathrm{v}$ hydrogen peroksida dan diwarnai (staining) dengan $.05 \%$ trypan blue dalam lactoglycerol $(\mathrm{b} / \mathrm{v})$ pada $70{ }^{\circ} \mathrm{C}$ selama $30-40$ menit (Kormanik dan Mc Graw, 1998) dalam Brundrett et al.,1996). Kolonisasi akar dihitung dengan menggunakan metode panjang akar terkolonisasi seperti yang digambarkan oleh Giovanneti dan Mosse (1980 dalam Brundret et al., 1996) dengan mikroskop compound.

\section{Analisis Data}

Hasil pengamatan dipaparkan secara deskriftif kuantitatif dengan menyajikan tabel jumlah spora, jenis spora, dan kolonisasi FMA pada berbagai media pembawa (zeolit, pasir, dan biocar)

\section{HASIL DAN PEMBAHASAN}

\section{Sifat Kimia Tanah}

Sifat kimia tanah merupakan salah satu faktor yang dapat mempengaruhi jumlah spora fungi mikoriza arbuskular. Hasil analisis kimia tanah pada lokasi pengambilan sampel dapat dilihat pada Tabel $2 \mathrm{~d}$ ibawah ini.

Tabel 2. Hasil Analisis Sifat Kimia Tanah pada perkebunan PT. Lembah Bhakti di Rawa Singkil

\begin{tabular}{ccccccc}
\hline $\begin{array}{l}\text { Sampel } \\
\text { Tanah }\end{array}$ & $\mathrm{pH}$ & $\begin{array}{c}\text { KTK } \\
\left(\mathrm{cmol} \cdot \mathrm{kg}^{-1}\right)\end{array}$ & $\begin{array}{c}\text { C-Organik } \\
(\%)\end{array}$ & $\begin{array}{c}\text { N-Total } \\
(\%)\end{array}$ & $\begin{array}{c}\text { P-Tersedia } \\
(\mathrm{ppm})\end{array}$ & $\begin{array}{c}\mathrm{K}-\mathrm{dd} \\
\left(\mathrm{cmol}^{-1} \mathrm{~kg}^{-1}\right)\end{array}$ \\
\hline 5 Tahun & 3,56 & 20,21 & 7,66 & 0,31 & 16,37 & 0,22 \\
10 Tahun & 5,98 & 6,74 & 3,71 & 0,18 & 15,80 & 0,16 \\
15 Tahun & 4,45 & 18,23 & 5,41 & 0,40 & 14,84 & 0,79 \\
\hline
\end{tabular}

Sumber: Hasil Analisis Laboratorium Departemen Ilmu Tanah Sumberdaya Lahan, Fakultas Pertanian, IPB (2016)

Kemasaman tanah dapat mempengaruhi populasi dan aktivitas mikroorganisme (Noor, 2001). Berdasarkan Kriteria Penilaian sifat kimia tanah (LPT, 1983) (Lampiran 1) pH tanah pada rizosfer kelapa sawit pada tiga tingkatan umur di perkebunan kelapa sawit PT. Lembah Bhakti di Lahan Gambut Rawa Singkil memiliki tingkat kemasaman yang berbeda-beda. $\mathrm{pH}$ tanah pada rizosfer kelapa sawit berumur 5 tahun dan 15 tahun tergolong kedalam kriteria yang rendah, sedangkan untuk sampel umur 10 tahun tergolong netral.

\footnotetext{
Eksplorasi Fungi Mikoriza Arbuskula pada Perkebunan Kelapa Sawit PT. Lembah Bhakti di Rawa Singkil dengan Kultur Trapping ( Safran, Ashabul Anhar, Fikrinda)

Jurnal Ilmiah Mahasiswa Pertanian Unsyiah, Vol. 2, No. 3, Agustus 2017: 38-48
} 
Nilai pH optimum untuk perkembangan FMA 5,6-7 untuk Glomus, pH 4-6 Gigaspora dan pH 4-5 Acaulospora (Tuheru, 2003).

KTK merupakan salah satu sifat kimia tanah yang dapat dijadikan sebagai indikator kesuburan tanah karena memiliki kaitan erat dengan ketersediaan hara bagi tanaman. Menurut Puspitasari et al. (2012) perkembangan FMA dan jumlah spora akan menurun seiring meningkatnya KTK tanah. Nilai KTK pada sampel umur 10 tahun tergolong rendah yaitu $6,74 \mathrm{cmol} \mathrm{kg}^{-1}$ dibandingkan dengan nilai $\mathrm{KTK}$ pada umur lainya yang tergolong kedalam kategori sedang (18,23-20,21 $\left.\mathrm{cmol} \mathrm{kg}^{-1}\right)$.

Kandungan C-organik tergolong sangat tinggi pada kelapa sawit umur 5 tahun dan 15 tahun yaitu 7,66 dan 5,41\% sedangkan pada sampel umur 10 tahun tergolong tinggi (3,71 \%). Menurut Nurhalimah et al. (2014) semakin tinggi kadar C-organik dalam tanah maka jumlah FMA juga semakin banyak.

Nilai $\mathrm{N}$ total pada umur kelapa sawit 10 tahun tergolong rendah $(0,18 \%)$ namun pada umur 5 dan 15 tahun tergolong sedang (0,31 dan 0,40\%). Menurut Setiadi et al, (1992) ketersedian unsur hara $\mathrm{N}$ yang rendah akan meningkatkan ketergantungan tanaman untuk berasoisiasi dengan mikoriza, karena ketersedian unsur hara yang rendah dapat mengoptimalkan mikoriza dalam penyerapan hara.

Menurut Octavianti, (2014) ketersediaan P yang tinggi pada tanah secara langsung dapat menurunkan aktivitas FMA, sehingga keberadaan FMA mengalami penurunan, sebaliknya pada $\mathrm{P}$ yang rendah dapat meningkatkan kolonisasi FMA dengan akar untuk meningkatkan luas kontak akar untuk mendapatkan unsur hara dari dalam tanah. Nilai $\mathrm{P}$ tersedia pada sampel umur 5 tahun lebih tinggi $(16,37 \mathrm{ppm})$ dibandingkan dengan nilai $\mathrm{P}$ tersedia untuk umur sampel 10 dan 15 tahun yang keduanya tergolong sedang (15,80 dan $14,84 \mathrm{ppm})$.

Kandungan $\mathrm{K}$ tanah juga dapat mempengaruhi perkembangan spora dan kolonisasi akar oleh FMA ( Nurhandayani et al, 2013). Kandungan K-dd untuk umur sampel 5 dan 10 tahun tergolong rendah $\left(0,20\right.$ dan $\left.0,16 \mathrm{cmol} \mathrm{Kg}{ }^{-1}\right)$, sedangkan untuk umur sampel 15 tahun tergolong tinggi dengan nilai K-dd $0,79 \mathrm{cmol} \mathrm{Kg}^{-1}$

\section{Jumlah Spora FMA}

Spora adalah komponen yang penting sebagai sumber inokulum dibandingkan potongan akar yang telah dikolonisasi oleh FMA (Kartika 2006). Berikut Gambar 3 menunjukan rata-rata jumlah spora pada berbagai umur kelapa sawit dengan kultur trapping. 


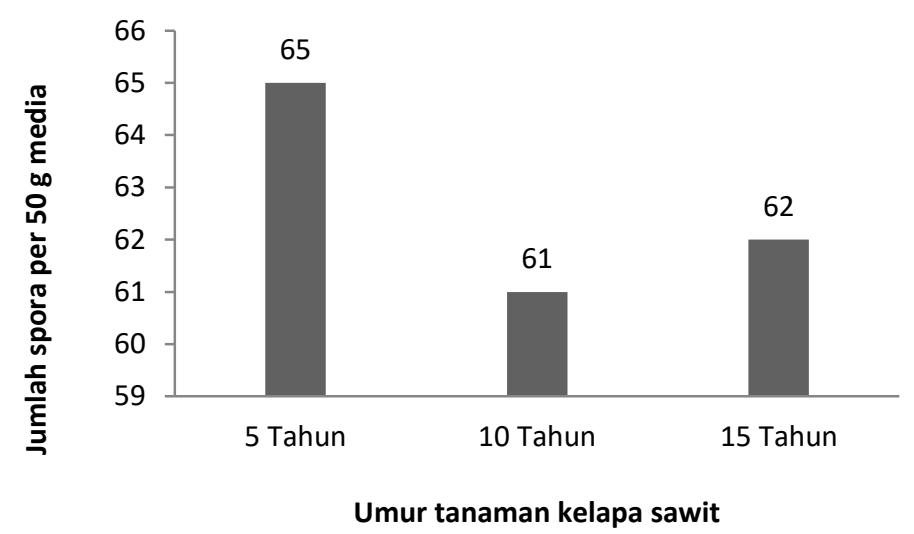

Gambar 3. Rata-rata jumlah spora FMA pada berbagai umur kelapa sawit

Jumlah spora FMA pada rizosfer kelapa sawit umur 5 tahun lebih tinggi dari pada umur 10 dan 15 tahun. Hal ini diduga berkaitan dengan nilai C-organik yang lebih tinggi dibandingkan pada rizosfer kelapa sawit umur lainnya. Menurut Nurhalimah et al. (2014) semakin tinggi kadar C-organik dalam tanah maka jumlah FMA juga semakin banyak. Menurut Muzakkir (2011) karena C-organik dapat menjamin mineralisasi yang hasilnya dapat menyediakan hara bagi simbiosis FMA dan tanaman.

Selain itu kondisi $\mathrm{pH}$ diduga juga mempengaruhi jumlah spora, dimana pada rizosfer kelapa umur 5 tahun memiliki derajat kemasaman yang rendah (masam) yang lebih sukai oleh FMA. Hal ini sesuai dengan pernyataan menurut Prihastuti (2007) menyatakan bahwa FMA dapat hidup dengan baik pada $\mathrm{pH}$ tanah masam dan mampu menghasilkan asamasam organik yang dapat membebaskan $\mathrm{P}$ terikat. Pengaruh media terhadap jumlah spora tertera pada Gambar 4.

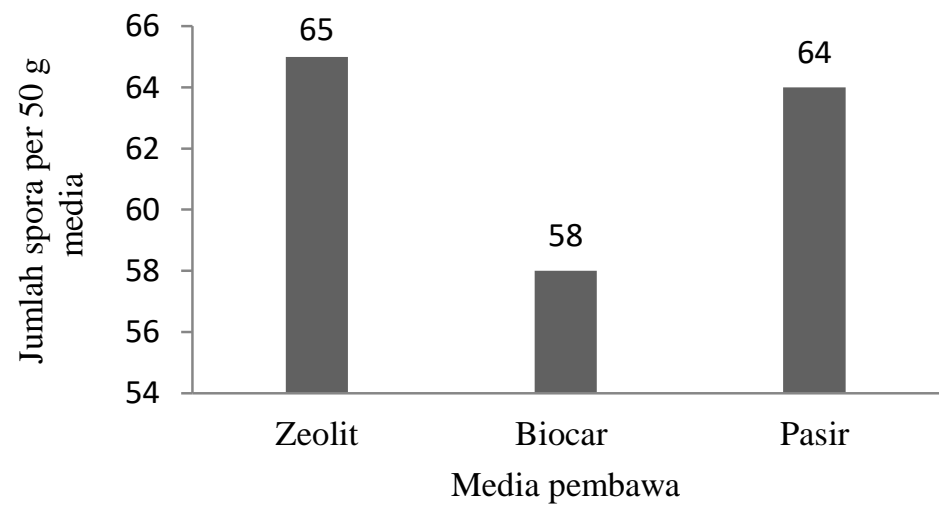

Gambar 4. Rata-rata jumlah spora FMA pada berbagai media pembawa

Ketiga media pembawa menunjukkan media zeolit mempunyai jumlah spora yang lebih tinggi dibandingkan media pasir dan biocar. Kartika (2006) menyatakan media zeolit menunjukkan jumlah spora yang lebih banyak dibandingkan dengan media tumbuh pasir. Hasil penelitian Denis et al. (2013) bahwa media tumbuh zeolit dan tanaman inang jagung menunjukkan hasil yang positif baik itu persentase infeksi maupun pada jumlah populasi spora FMA. 


\section{Keragaman Spora FMA}

Keragaman FMA pada berbagai media pembawa dan umur tanaman kelapa sawit PT. Lembah Bhakti di Lahan Gambut Rawa Singkil tertera pada Tabel 3 dan 4.

Tabel 3. Jumlah FMA dan Keragaman FMA pada Berbagai Media Pembawa

\begin{tabular}{lccccc}
\hline \multirow{2}{*}{$\begin{array}{l}\text { Media } \\
\text { Tanam }\end{array}$} & Acaulospora sp1 & Glomus sp1 & Glomus sp2 & Glomus sp3 & Glomus sp4 \\
\hline Zeolit & 16 & 18 & 7 & 7 & 17 \\
Pasir & 14 & 17 & 8 & 8 & 16 \\
Biochar & 15 & 14 & 7 & 8 & 15 \\
\hline Rata-Rata & 15 & 16 & 7 & 8 & 16 \\
\hline
\end{tabular}

Tabel 4. Jumlah FMA dan Keragaman FMA pada Berbagai Umur Kelapa Sawit

\begin{tabular}{lccccc}
\hline \multirow{2}{*}{$\begin{array}{l}\text { Umur } \\
\text { Tanaman }\end{array}$} & Acaulospora sp1 & Glomus sp1 & Glomus $\mathrm{sp2}$ & Glomus sp3 & Glomus sp 4 \\
\cline { 2 - 6 } & & 17 & 7 & 8 & 17 \\
\hline 5 Tahun & 16 & 16 & 7 & 8 & 16 \\
10 Tahun & 14 & 16 & 8 & 8 & 16 \\
15 Tahun & 15 & 16 & 7 & 8 & 16 \\
\hline Rata-Rata & 15 & &
\end{tabular}

Hasil penelitian ini menunjukkan terdapat dua genus FMA pada rizosfer kelapa sawit berbagai umur dan media pembawa yaitu Acaulospora dan Glomus. Glomus merupakan genus dominan yang ditemukan pada berbagai umur tanaman kepala sawit dan berbagai media pembawanya. Menurut Suamba et al. (2014) Glomus memiliki adaptasi yang sangat luas, sehingga hampir ditemukan di berbagai kondisi lingkungan. Hasil yang sama juga ditemukan oleh Husin et al. (2007) yang telah mengobservasi dan mengidentifikasi spora FMA jenis Glomus sp. dalam jumlah dominan pada berbagai rhizosfir tanaman di lahan kritis Sumatera.

Pada penelitian ini terdapat beberapa spesies spora FMA yaitu Acaulospora sp 1, Glomus sp 1, Glomus sp 2, Glomus sp 3, Glomus sp 4. Dari kedua spesies, Glomus sp1. merupakan spesies yang dominan dijumpai dibanding acaulospora sp. Karaktristik spesies spora FMA yang ditemukan pada berbagai umur kelapa sawit dengan berbagai media pembawanya terdapat pada Tabel 5. 
Tabel 5. Karaktristik spora FMA yang ditemukan pada berbagai umur kelapa sawit dengan berbagai media pembawanya

\begin{tabular}{|c|c|c|c|}
\hline No & Genus FMA & Deskripsi & Dokumentasi \\
\hline 1 & Acaulospora sp1 & $\begin{array}{l}\text { Spora dari genus Acaulospora } \\
\text { dengan ukuran }>100 \mu \mathrm{m} \text {, } \\
\text { ornament berupa lubang (pitted), } \\
\text { berwarna bening kekuningan }\end{array}$ & \\
\hline 2 & Glomus sp1 & $\begin{array}{l}\text { Spora dari genus Glomus dengan } \\
\text { ukuran }<100 \mu \mathrm{m} \text {, bewarna bening }\end{array}$ & \\
\hline 3 & Glomus sp2 & $\begin{array}{l}\text { Spora dari genus Glomus dengan } \\
\text { ukuran }<100 \mu \mathrm{m} \text {, bewarna kuning } \\
\text { tua }\end{array}$ & \\
\hline 4 & Glomus sp3 & $\begin{array}{l}\text { Spora dari genus Glomus dengan } \\
\text { ukuran }<100 \mu \mathrm{m} \text {, bewarna merah } \\
\text { kecoklatan }\end{array}$ & \\
\hline 5 & Glomus sp4 & $\begin{array}{l}\text { Spora dari genus Glomus dengan } \\
\text { ukuran }<100 \mu \mathrm{m} \text {, bewarna kuning }\end{array}$ & \\
\hline
\end{tabular}

\subsection{Kolonisasi FMA}

Kolonisasi akar FMA ditandai dengan ditemukannya struktur-struktur dari FMA yang mengisi sel korteks seperti arbuskular, versikel, hifa maupun spora (Setiadi \& Setiawan, 2011). Infeksi akar merupakan bentuk awal dari simbiosis antara FMA dengan akar tanaman (Chalimah, et al., 2007). Kolonisasi akar dapat mencerminkan tingkat asosiasinya antara FMA dengan tanaman. Rata-rata kolonisasi FMA pada berbagai umur dan media pembawanya dapat dilihat pada Gambar 5. 


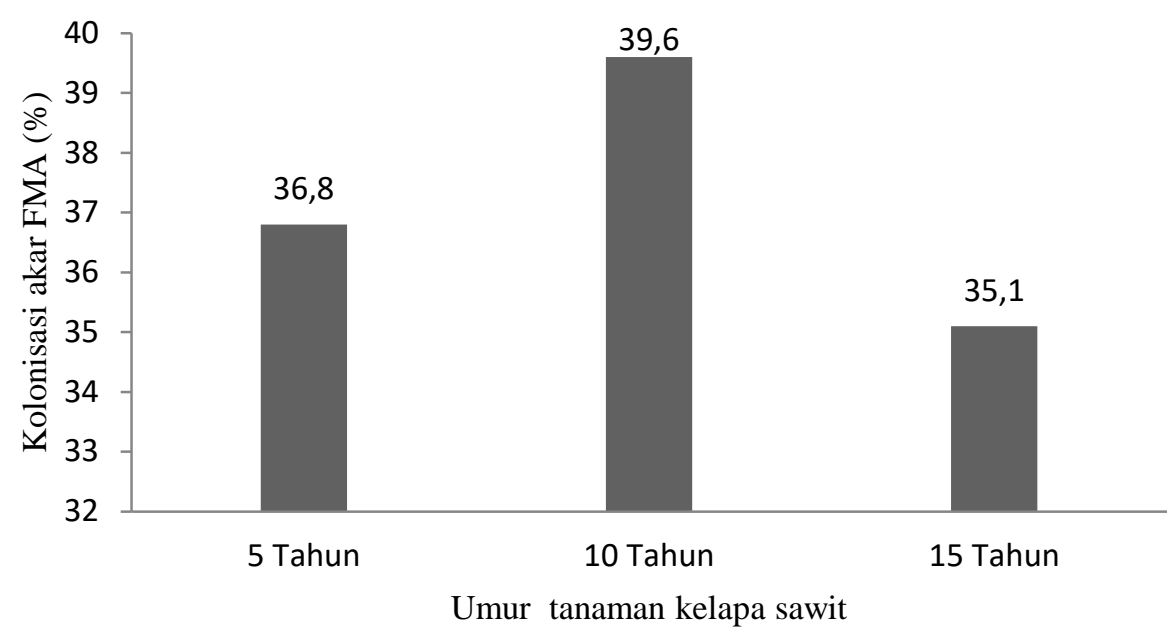

Gambar 5. Rata-rata kolonisasi FMA pada berbagai umur tanaman kelapa sawit.

Umur kelapa sawit menunjukkan bahwa kolonisasi FMA paling tinggi dijumpai pada umur 10 tahun. Hasil penilitian Arman et al., (2015) menunjukan bahwa kolonisasi FMA pada berbagai umur tanaman kelapa sawit tertinggi dijumpai pada umur 2-3 bulan. Hal ini diduga kolonisasi akar yang tinggi terjadi berhubungan dengan nilai KTK yang rendah, sehingga merangsang akar FMA untuk memperluas kontak dengan tanah untuk menyuplai hara bagi tanaman. Menurut Puspitasari et al. (2012) KTK tanah mempengaruhi perkembangan FMA dan jumlah spora akan menurun dengan meningkatnya KTK tanah. KTK merupakan sifat kimia yang sangat erat hubungannya dengan kesuburan tanah. Tanah dengan KTK tinggi mampu menyerap dan menyediakan unsur hara lebih baik dari pada tanah dengan KTK renda (Hardjowigeno, 1993). Kolonisasi FMA pada akar tanaman jagung dari kultur trapping pada berbagai media pembawa dapat dilihat pada Gambar 6.

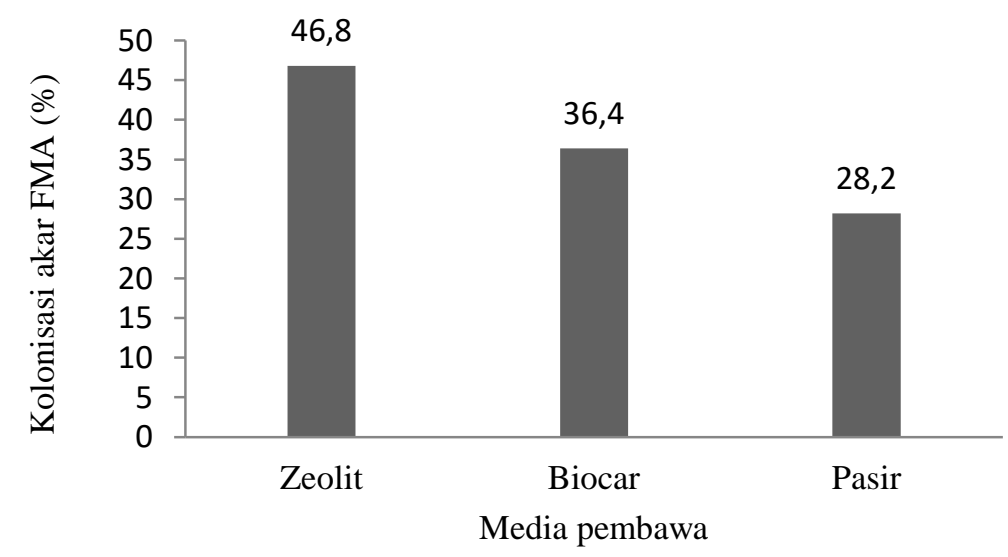

Gambar 6. Rata-rata kolonisasi FMA pada berbagai media pembawa

Dari ketiga media pembawa termasuk kedalam kategori sedang (26-50\%). Tetapi media zeolit memiliki tingkat kolonisasi FMA lebih tinggi dibandingkan media lainnya. Media zeolit diduga memiliki pori-pori yang terbentuk lebih besar sehingga memiliki aerasi yang lebih baik untuk perkembangan FMA. Menurut Denis, et al. (2012) perbedaan jumlah persentase kolonisasi akar dikarenakan masing-masing media mempunyai kadar, struktur, dan karakteristik hara yang berbeda untuk mendukung perkembangan spora dan hifa FMA, sehingga didapat jumlah persentase infeksi FMA yang berbeda pula. Kolonisasi FMA pada akar ditunjukkan pada Gambar 7. 


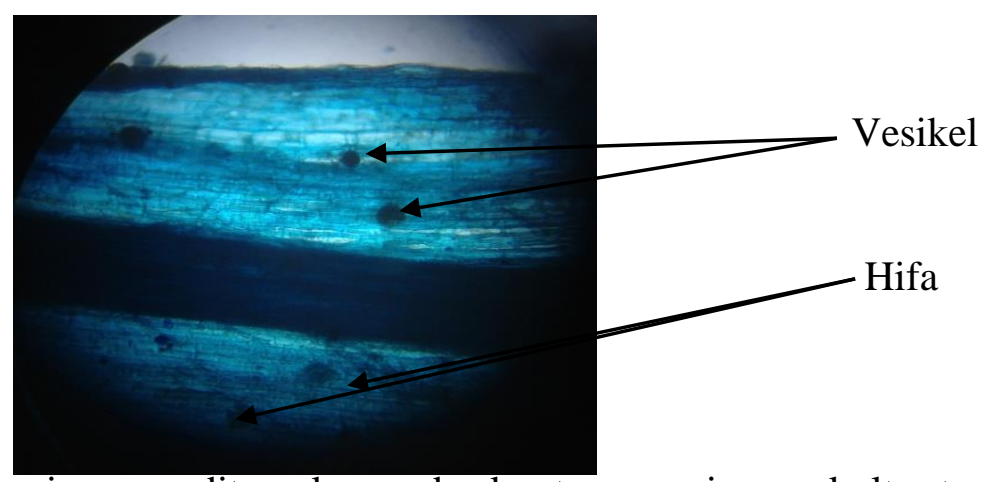

Gambar 7. Struktur mikoriza yang ditemukan pada akar tanaman jagung kultur trapping

Hasil menunjukkan tingginya jumlah spora tidak diikuti dengan tingkat kolonisasi akar yang tinggi pula. Hal ini yang sama juga ditunjukan oelh Tuheteru (2003)

\section{SIMPULAN DAN SARAN}

Jumlah spora pada umur 5 tahun memiliki jumlah lebih tinggi dibandingkan pada umur 10 tahun, dan 15 tahun. Media zeolit menunjukan jumlah spora dan persentase kolonisasi lebih tinggi dibandingkan pasir dan biocar. Terdapat dua genus pada rizosfer kelapa sawit berbagai umur dan media yaitu Glomus dan Acaulosspora. Glomus merupakan genus yang doniman yang ditemukan. Saran dari penelitian ini adalah perlu penelitian lanjut terhadap perbanyakan FMA lokal terkait potensinya sebagai pupuk hayati. Eksplorasi FMA juga perlu dilakukan di lokasi lain dengan jenis tanaman yang sama atau berbeda karena sebaran dan keragaman fma berbeda pada kondisi tanah, tanaman, dan pengelolaan yang berbeda.

\section{DAFTAR PUSTAKA}

Ariantiningsih, F. 2008. Suaka Marga Satwa Aceh Singkil Program Kampanye Banga. Yayasan Ekosistem Lestari, Medan.

Arman, A. R., Fikrinda, Muyasir, A. Anhar, N. F. Mardatin dan T. Arabia. 2015. Status fungi mikoriza arbuskula pada berbagai sistem pengelolaan dan umur tanaman kelapa sawit. Floratek 10 (2): 12-18.

Bolan, N. S. 1991. A Critical Review on The Role of Mycorhizal Fungi in The Uptake of Phosphorus by Plant. Plant and Soil 134:189-207.

Brundrett.M, L. Melville, and L. Peterson. 1994. Practical methods in mycorrhiza research. Mycologue Publications, p. 95- 100.

Brundrett, M., N. Bougher, B. Dell, T. Grave and N. Malajezuk. 1996. Working with Mycorrhiza in Forestry and Agriculture. Australian Centre for International Agricultural Research (ACIAR), Canberra, Australia.

Brundrett, M. 2004. Diversity and Classification of Mycorrhizal Associations. Biology Review. 79: 473 - 495.

Brundrett, M., N. Bougher, B. Dell, T. Grove, and N. Malajeczuk. 2008. Working with Mycorrhizas in Forestry and Agriculture. Australian Centre for International Agriculture Research, ACIAR Monograph 32. Canberra. Australia. 
Chalimah, S, Muhadiono, L Azman, S Haram dan N Toruan, 2007. Perbanyakan Gigaspora sp. dan Aclaulospora sp, dengan kultur pot di rumah kasa. Biodiversitas 7: 12-19.

Denis, P., T. S. Haryani, dan O. Trisilawati. 2012. Efektivitas Media dan Tanaman Inang untuk Perbanyakan Fungi Mikoriza Arbuskular (FMA). Biodiversitas. 64 : 394-399

Djufri., Abdullah dan Muchlisin. 2013. Biodiversitas. Scientific Studies For The Rehabilitation and Mangement of The Tripa Peat-swamp Forest. Project Implementation Unit. Universitas Syiah Kuala. Banda Aceh.

Guadarrama P., S. Castillo-Arguero., J.A. Ramos-Zapata. 2008. Propagules of arbuscular mycorrhizal fungi in secondary dry forest of Oaxaca, Mexico Tropica Biologi 56 (1) : 269-277.

Hardjowigeno, S. 1993. Klasifikasi tanah dan Pedogenesis. Akademika Pressindo. Jakarta.

Husin, E. F., Marlis, R., Trimitri., Auzan., Burhanuddin., dan Zelfi, Z. 2007. Observasi dan identifikasi spora Cendawan Mikoriza Arbuskular (CMA) pada berbagai rhizosfir di lahan kritis Sumatera. Disajikan pada Se-minar Nasional Mikoriza "Percepat-an Sosialisasi Teknologi Mikoriza untuk Mendukung Revitalisasi Ke-hutanan, Pertanian dan Perkebunan. Sri W.B, Maman T, Noor F.M, Abimanyu D.N, Octivia T, Irnayuli R.S, Arum S.W, Melya R, Luluk S (eds). Bogor, 19-20 Juli 2007.

Kartika, E. 2001. Isolasi, Karakterisasi dan pengujian keefektifan cendawan mikoriza vesikula arbuskular terhadap bibit kelapa sawit pada tanah gambut bekas hutan. Agronomi 10 (2) : 63-70.

Kartika, E. 2006. Isolasi, karakterisasi dan pemurnian CMA dari tiga lokasi perkebunan kelapa sawit (tanah PMK bekas hutan, PMK bekas kebun karet, dan gambut bekas hutan).Disertasi.Sekolah Pasca sarjana Institut Pertanian Bogor. Bogor.

Muzakkir. 2011. Hubungan Antara Cendawan Mikoriza Arbuskula Indigeneous dan Sifat Kimia Tanah di Lahan Kritis Tanjung Alai, Sumatera Barat. Sains dan seni 8 (2) : 53-57.

Noor, M., 2001. Pertanian Lahan Gambut.Kanisius. Yogyakarta.

Nurbaity, A., Herdiyantoro, D \& A. Setiawan. 2008. Aplikasi Fungi Mikoriza Arbuskula dan Bahan Organik Untuk Meningkatkan Ketahanan Tanaman Sorgum Terhadap Kekeringan. Kukuh M, Fahmuddin A, Suria D. Tarigan, Ai D, Neneng L. Nurida, Harry S, Naik, dan Ngaloken A G. (ads). Seminar dan Kongres Nasional Masyarakat Konservasi Tanah Indonesia ke VI. Biologi 13 (1) : 17- 11

Nurbaity A., D. Herdiyantoro dan O. Mulyani. 2009. Pemanfaatan bahan organik sebagai bahan pembawa inokulan fungi mikoriza arbuskula. Biologi 13 (1) : 17- 11

Nurhalimah, S., S. Nurhatika, dan A. Muhibuddin. 2014. Explorasi Mikoriza Vesikular Arbuskular (MVA) Indegenus pada Tanah Regosol di Pamekasan, Madura. Jurnal Sains dan Seni Pomits. 3 (2) :30-34

Nurhandayani, R., R. Linda, dan S. Khotimah. 2013. Inventarisasi Jamur Mikoriza Vesikular Asbukular dari Rhizosfer Tanah Gambut Tanaman Nanas (Ananas comosus (L.) Merr). Jurnal Protobiont. 02:146-251. 
Octavianti, E.N., \& D. Ermavitalini. 2014. Identifikasi mikoriza dari lahan Desa Poteran, Sumenep Madura. Sains dan Seni Pomits 3 (2): 2337-3520

Prasetia, D. 2012. Efektivitas Media Dan Tanaman Inang Untuk Perbanyakan Fungi Mikoriza Arbuskular (FMA). Fakultas MIPA, Universitas Pakuan, Bogor.

Prematuri, R., dan Noor Faiqoh. 1999. Produksi Inokulum Cendawan Mikoriza Arbuskula. Laboratorium Bioteknologi Hutan, PAU Bioteknologi IPB.

Prihastuti. 2007. Isolasi dan karakterisasi mikoriza vesikular-arbuskular di lahan kering masam, Lampung Tengah. Berk. Penel. Hayati: 12 : 99-106.

Puspitasari D., K. I. Purwani., \& A. Muhibuddin. 2012. Eksplorasi vesicular mycorrhiza indigenous pada lahan jagung di Desa Torjun, Sampang Madura. Surabaya. Sains dan Seni $1: 19-22$.

Redecker, D.,H., Thierfelder, and D. Werner. 1998. Production Of Biomass Of Arbuscular Mycorrhizal Fungi in The Glass Bead Compartment system. In Mycorrhiza Manual Ed: A.Varma, Springer, New York.

Rengganis, D. 2013. Studi Keanekaragaman Genus Fungi Mikoriza Arbuskula Di Sekitar Perakaran Pohon Jabon (Anthocephalus cadamba Roxb Miq) Alami. Institut Pertanian Bogor. Bogor

Setiadi, Y. \& A. Setiawan. 2011. Studi status Fungi Mikoriza Arbuskular di areal rehabilitasi pasca penambangan nikel (Studi kasus PT. INCO Tbk. Sorowako, Sulawesi Selatan) Silvikultur Tropika 3 (1):88-89.

Sibarani, A.S. 2011. Keanekaragaman Fungi Mikoriza Arbuskula (FMA) pada tegakan karet dan tegakan sawit di ekosistem lahan gambut Desa Telaga Suka Kecamatan Panai Tengah Kabupaten Labuan Batu. Skripsi. Fakultas Pertanian, Universitas Sumatera Utara, Medan.

Siregar, R.A.D. 2014. Keanekaragaman Fungi Mikoriza Arbuskula pada Areal Tanaman Karet (Studi Kasus di PTPN III Kebun Batang Toru Kabupaten Tapanuli Selatan. Skripsi. Fakultas MIPA, Universitas Sumatera Utara, Medan

Smith, S.E., and D.J. Read. 2008. Mycorrhizal symbiosis. 3rd ed. Academic Press. San Diego, USA.

Suamba I.W., I.G.P. Wirawan dan W. Andriatayasa. 2014. Isolasi dan identifikasi fungi mikoriza arbuskular (FMA) secara mikroskopis pada rhizosfer tanaman jeruk (Citrus sp) di Desa Kerta, Kecamatan Payangan, Kabupaten Gianyar. Argroekoteknologi Tropika 3 (4) : 201-208.

Tuheteru FD. 2003. Aplikasi Asam Humat terhadap Sporulasi CMA dari bawah Tegakan Alami Sengon. Skripsi. Fakultas Kehutanan, Institut Pertanian Bogor. Bogor

Widiastuti, H. 2006. Infektivitas dan evektivitas propagul mikoriza arbuskula yang diisolasi dari beberapa rhizosfer kelapa sawit. Agronomi 10 (1): 33-36. 